\title{
Castigos y marcas: Historias de abusos contra el pueblo mapuche
}

Estamos reunidos aquí para poder tener una justicia, lo que quería mi hijo y por eso estamos aquí. Mi hijo luchaba por el futuro de la familia que venía, por poder tener un pedazo de pan en la tarde. Él me dijo que iba a ir a conversar qué dice el rico, para poder o vender o no. Salió y no llegó más. Lo mataron (....) todos los días andan los carabineros, rodeando a los mapuche, escuchando qué es lo que dicen, como que fuéramos delincuentes. El mapuche lucha por la tierra, para poder tener un pedazo de pan el día a día.

Sra. Rosa Collío, madre de Jaime Mendoza Collío.
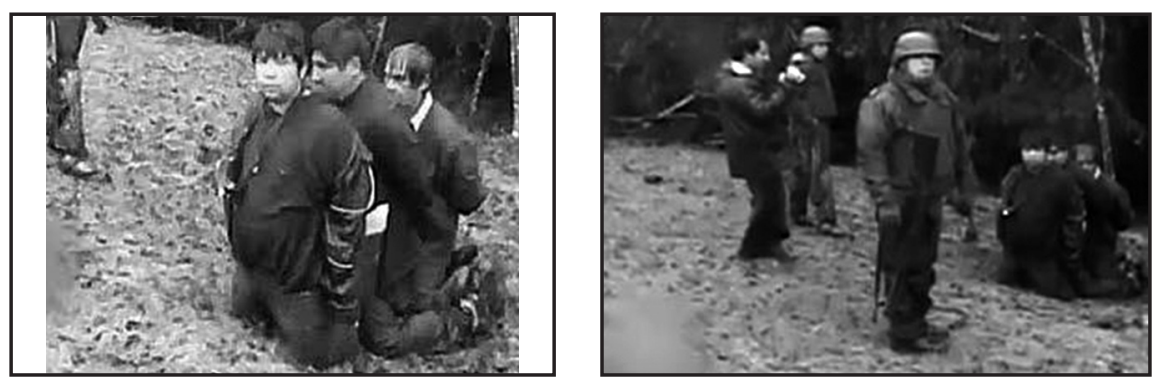

Triste Realidad: Maltrato al Pueblo Mapuche

ASÍ MUESTRAN A LOS COMUNEROS MAPUCHE DETENIDOS HOY EN VILCUN. ARRODILLADOS Y GOLPEADOS COMO SI FUERAN PRISIONEROS DE GUERRA. HUMILLACIÓN EXTREMA AL PUEBLO MAPUCHE.

DETENIDOS LOS COMUNEROS: Mario José Cheuque Sandoval (36), Bernardo Carrillán Trupán (62) y Ernesto Gabriel Chachallao Painemil (36), uno los líderes de la Coordinadora Arauco Malleco (CAM). 


\section{Fiscalía retrocede y decide no seguir con montaje contra 3 mapuche de Vilcún}

Nov 03, 2012

El pasado 26 de octubre el Ministerio Público presentó ante el Juzgado de Garantía de Temuco su decisión de no seguir adelante con las graves acusaciones hacia tres mapuche de Yeupeko en Vilcún, detenidos y agredidos hacía ya tres meses.

La policía destruyó las rukas, rociaron con nafta nuestras quintas, nos llevaron la mesa, la olla, la parrilla, hicieron un asado con la madera de nuestras rukas, colgaron un perro con alambre hasta matarlo y lo tiraron en la ruka, la policía corre a la gente por el bosque... Cuelgan botellas y hacen tiro al blanco, han venido con sus perros, nos arrinconan, saquean, reprimen, muchos han perdido su trabajo por no poder bajar al pueblo y tampoco podemos bajar a comprar alimentos. Yo he vivido siempre en la comunidad, yo tengo tres hijos y la placenta de mis tres hijos están enterradas en estas tierras... La legitimidad sobre el territorio no nos la quita nadie, tenemos una lucha fuerte, la territorial, porque pone en juego intereses económicos y por ello tenemos muertos.

Relato de una anciana consignado en el Informe de situación, Comunidad Paichil Antriau, Villa La Angostura, Argentina. Hace referencia al desalojo de la comunidad Paichil Antriau ejecuado por la policía neuquina el 2 de diciembre de 2009, a partir del reclamo realizado por el empresario norteamericano William Fischer.

En Historias de las Familias Mapuche Lof Paichil Antriao y Lof Quintriqueo. Mapuche de la Margen Norte del Lago Nahuel Huapi. Villa La Angostura: Archivos del Sur - Biblioteca Popular Osvaldo Bayer, 195, 2010.

Bueno el territorio mapuche Juan Kurrin aquí la comunidad.... Casi pura usurpación. Nosotros vivimos la usurpación, cuando estábamos, cuando éramos niños. Cómo llegaron los chilenos se tomaron ahí, se tomaron los terrenos, cómo amenazaban a mi papá cuando llegaron ahí... a pesar que eran del gobierno de la Unidad Popular, de Salvador Allende, el MIR apoyó esa toma, porque las personas eran de la izquierda, los que se tomaron 
ahí, y mi papá cuando pasaba para allá lo amenazaban, lo amenazaban con una pistola, me acuerdo siempre un compadre joven, iba conmigo y tenía que pasar por otro lado para que no pasara por ahí, le prohibieron la pasá, para ir a ver a su hermano que vivía más arriba y así pudo toda esa gente.

Entrevista a la Sra. Ana Catrileo, Febrero de 2013. Comunidad Juan Kurrin, en la periferia de Temuco. Entrevista realizada por Cristián Huenuvil en el marco de la tesis "Re significación del Territorio a partir de una Acción de Arte: Un recorrido por el antiguo del Lof Juan Kurrin" para Licenciatura en Artes. Universidad Católica de Temuco, Marzo de 2013.

\section{Sentencia de Juana Catrilaf, acusada del homicidio de una machi}

C. de Valdivia. -7 de diciembre de 1953.

La víctima: de raza araucana. Lo prueban su apellido, el lugar de residencia, su vestimenta (acta de fojas 2). Ejercía de machi o curantera y de hechicera en la región donde habitaba (declaraciones de José Queupumil, de fojas 10, de Antonio Queupumil, de fojas 11 vuelta, Juan Catalán, fojas 10 vuelta, Julio Calfiñanco, de fojas 20, Artemio Calfiñanco, de fojas 21, Saturio Calfiñanco, de fojas 22, Federico Catrilaf, de fojas 22 vuelta, Antonio Catrilaf, de fojas 23, Emelina Queupumil, de fojas 23 y Lisandro Queupumil, de fojas 23 vuelta). Se la buscaba para machitucar, es decir, para curar a los embrujados (Juan Catalán, fojas 19 vuelta), para hacer curaciones de enfermos (todas las declaraciones anteriores), para efectuar guillatunes (Federico Catrilaf, fojas 22 vuelta) y para hacer brujerías (Antonnio Catrilaf, fojas 23, Saturio Calfiñanco, fojas 22). Se la temía porque daba venenos a la gente con quien estaba mal (Antonia Catrilaf, fojas 23, Lisandro Queupumil, fojas 23 vuelta), porque "con venenos y sortilegios mataba a la gente y especialmente a los niños" (los de las declaraciones anteriores). Era abuela de la reo y tenía 84 años de edad (92).

Extracto del expediente de Juana Catrilaf Calfiñanco, mujer de 27 años, que fue llevada a juicio en 1953 acusada del homicidio de su abuela Antonia Millalef, quien era machi de su comunidad. Finalmente, Juana Catrilaf quedó "exenta de responsabilidad penal, por haber actuado bajo el imperio 
de una fuerza psíquica irresistible, una india mapuche, procedente de una tribu carente totalmente de cultura, que da muerte a otra" (p. 85).

Fuente: sentencia facilitada por Myrna Villegas.

\section{La marcación de mapuche fue una práctica bastante usada en Chile,} especialmente en el proceso de reducción del territorio mapuche. Hay testimonios de parientes a los cuales les cortaron un pedazo de oreja, o de la marcación a fuego; ambas prácticas utilizadas con los animales:

Mi abuelito era de Cayucupil, vivían ahí cuando llegaron los franceses, les arriaron con la tierra, los cercaron y no lo dejaron salir más. Cuentan que mi abuelito no aguanto que lo dejaran así y lo tomaron y le cortaron las orejas, le dejaron la parte de arriba no más. Yo lo conocí viejito con sus orejas cortadas.

Testimonio de Alamiro Huequilao de Cayucupil, provincia a de Arauco. Ver José Bengoa. Historia del Pueblo Mapuche Siglo XIX y XX. Santiago de Chuile: Ediciones Sur. Colección Estudios Históricos, 379, 1991.

La marcación de don Juan M. Painemal marcó un antes y un después en las movilizaciones mapuche de inicios del siglo XIX. Juan Painemal, fue secuestrado y humillado por unos agricultores de Nueva Imperial en 1913 y marcado a fuego. Esta irracional y cobarde acción generó la primera movilización masiva de protesta posreduccional, liderada por la Sociedad Caupolicán.

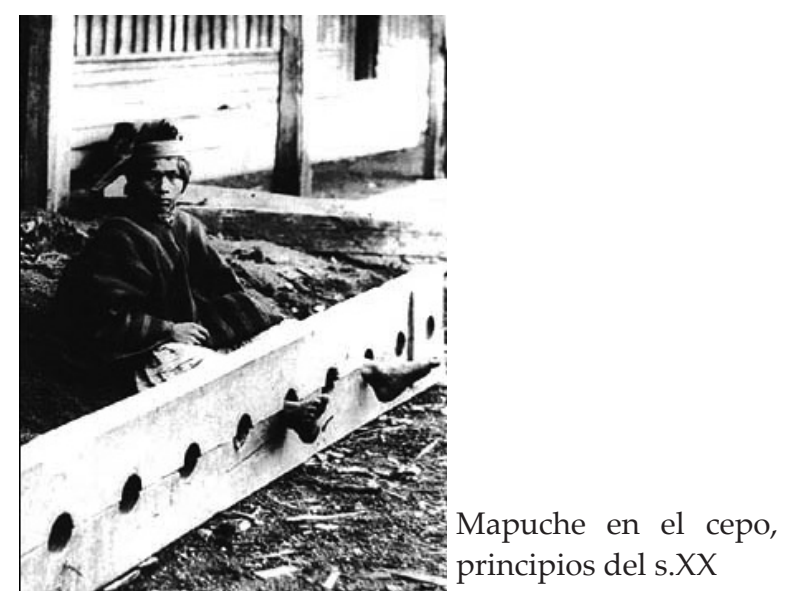


DENUNCIO CRIMINALMENTE CONTRA LAS PERSONAS QUE INDICAN POR DELITOS DE HOMICIDIO Y SE TOME LA INFORMACIÓN DE TESTIGOS. OTROSÍ QUE EL EXCMO. SEÑOR PRESIDENTE DE LA REPÚBLICA ENVÍE UN MINISTRO DE LA ILUSTRÍSIMA CORTE DE VALDIVIA PARA LAS INVESTIGACIONES LEGALES; AL JUZGADO DE PUERTO MONTT, PROVINCIA DE LLANQUIHUE.

Francisco Nailef, Juan de Dios Niapan, José Santos Maitri, Esteban Caniupán, José Manuel Menco, Caciques, todos agricultores... Al Señor Excmo. Presidente de la República con todo respecto exponemos:

Que denunciamos criminalmente en contra de Edmunso Winkler, Guillermo Held, Carlos Hechenleitner, agricultores y todos domiciliados en la $3^{\circ}$ subdelegación del Departamento de Llanquihue y provincia del mismo nombre por los delitos de homicidio y asaltos y muerte en la persona de Juan Pailahueque ya finado con cinco balas en diferentes partes del cuerpo (...) y a un hijo que tiene cuatro balazos en el cuerpo y está gravemente herido y que se encuentra en el Hospital de Puerto Montt.

Que desde varios años hasta esta fecha se nos viene molestando de miles de manera ya sea por medio de lanzamientos, asaltos robos y asesinatos que sin miramiento alguno ni respeto a las autoridades nos siguen molestando los particulares Chilenos y los Colonos Extranjeros nada más que por el hecho que todas estas personas tratan y han tratado de acabar con todo lo que tenemos y además con nuestras vidas".

José Santos Maitri

A ruego por los caciques que no saben firmar Enrique Pinuer R.

En Eugenio Alcamán. “Memoriales Mapuche -Williches. Territorios Indígenas y Propiedad Particular (1793-1936)". Original: Archivo Nacional de la Administración (ARNAD), Fondo Ministerio de Relaciones Exteriores, Vol.2056. 
Las abuelas del lado de mi mamá eran goluches, venidas de Chile. La más brava criaba solamente nietas mujeres, varones no. Me parece que la razón era que no los iba a poder dominar. Los Epulef también eran goluches. Eran mapuches rubios, con cara pecosa y la piel bien blanca.

Antiguamente, la gente no era como nosotros. Ahora nos quedamos y nos establecemos; ellos caminaban mucho. Cruzaron Chile en balsa por los lagos con los animales. Cuando los traían, les costaba llegar, venían en etapas. Vinieron acá porque había mejores lugares, más tierras para tener animales.

La abuela Rosa, mi otra abuela materna, se casó en Argentina, pero quedó viuda de jovencita. Le mataron al marido para robarle todo. La abuela se escondió con el hijito debajo de la cama y así se salvó si no se la llevaban. Antes se llevaban a las mujeres y dejaban a los chicos para matarlos. Era gente bandolera, eran blancos. Eran los malones. Formaban un ejército y se llevaban cautivas a todas las personas jóvenes. Mataban a la gente que tenía capitales. Ésa es la vivencia del pasado de mi abuela, de mi mamá. Los mapuches sufrieron mucho. Ahora es diferente: al mapuche se lo respeta. Yo tengo muchas amistades con la gente blanca y me aprecian mucho. Aunque me ven como mapuche, soy muy querida y respetada.

Testimonio de Teresa Epulef, nacida el año 1937 en Río Negro, Argentina. Forma parte de la comunidad Mongell Mamuell.

(En Mujeres dirigentes indígenas, relatos e historias de vida. Buenos Aires: Secretaría de Cultura de la Presidencia de la Nación, 137-138, 2008).

... Sólo tuvo tres hijos hombres: Külapang, Epulew y Kallfükew. Murió de calentura. Otros dicen que fue de brujería. Murió en Adenkul [en 1861]. Antes de morir llamó a sus hijos. Les aconsejó que no se rindieran a los chilenos, porque les robarían sus terrenos y esclavizarían a sus hijos. Así se lo prometieron.

Creía que con su muerte se entrarían los winka. Lo enterró su hijo Külapang con una casaca galoneada que le había regalado el general Cruz. El entierro se efectuó ocultamente. Nadie supo dónde quedó.

Más tarde Külapang huyó de Chanko [un poco al sur de 
Adenkul]. El ejército chileno lo perseguía sin descanso. Se refugió en Lonkoche (cerca del pueblo de Lautaro). Ahí llevó la canoa en que estaba su padre. La llevó en carreta. La puso en un sitio oculto donde no pudiesen hallarla los soldados chilenos. Todos creían que si los soldados tomaban las cosas y los restos de Mangiñ, se parecerían a él [por transmisión mágica]. Entonces no podrían vencerlos...

En Tomás Guevara y Manuel Mañkelef. KIÑE MUFÜ TROKIÑCHE ÑI PIEL Historias de familias Siglo XIX. Capitulo X "PU MANGIÑ Los Mangiñ de Juan Kallfükura y José Manuel Zúñiga”. Temuco: Colibris Liwen, 2002.

...No me gusta acordarme de lo que he vivido, yo creo que esto me lo hacen por mi familia, por lo que ellos reclaman. A veces llegan los pacos allá donde estoy cuidando animales y me amarran por harto rato a los arbustos; dicen que andan buscando animales que se robaron, pero nunca me han encontrado nada... A veces me cuesta mucho dormir, me despierto en la noche y ya no me puedo quedar dormido....

P.Q.M., 16 años, comunidad Temucuicui.

Ahí toqué yo igual, nunca me habían pegado, así igual antes me pegaban pa' que me quedara callado, pero esta vez me pegaron fuerte. (...). Yo creo que me vieron más grande, así como que podía hacer algo, no sé. Nosotros estábamos en la casa y no sé por qué vinieron a allanar, porque parece que habían tomado preso a mi hermano o algo así.

Niño, comunidad mapuche, comuna de Ercilla.

Informe sobre Violencia Institucional hacia la Niñez Mapuche en Chile. Realizado por la Fundación ANIDE, año 2012.

José Colleuque: ngillatun (fragmento)

Ingeniero Jacobacci, Río Negro

Asamblea del Consejo Asesor Indígena, 14/03/87 
Pichi ngillatulelafiin, wenu rey chao wenu rey ñke müley Un poco le vamos a hacer rogativa, padre rey del cielo madre reina del cielo están fey ta newenmannieymu, fey ta trapuntuaeymu ta ta trawtuy ustedes dos dan fuerza, así ambos vuelven a juntar, se reúnen ellos.

Küme norküleay iñ piwke, kiñe, kiñe, kiñeay rakizuam, fey chi küme amuayiñ

que esté bien derecho nuestro corazón, que se haga uno el pensamiento, así vamos a andar bien.

Kiñenoley rakizuam, küme amulay Si no es uno el pensamiento, no va bien.

Siempre, feymu fütake che kuyfi epikefuy, kiñeaymi rakizuam Siempre, por eso la gente anciana antes decía siempre: "Hacé uno el pensamiento. Fey ta kümey amuaymün, dios ta kelluaymün, dios ta, eleymu Así van a andar bien ustedes, dios los va a ayudar, dios que los dejó.

Wenu rey chao wenu rey ñuke ta müley, fey ta newenmaeymün piki Está el padre rey del cielo, la madre reina del cielo, así ustedes son fuertes", decían. Fey pichi ngillatulelafiin tati Eso les voy a rogar un poco.
Feymu ta kimn, kiñeke ta kimi, kimafuy ña zunguy

Porque sé, cada uno sabe, si sabe, habla.

Kimey chi ta iñ ngillatulelafiel Es lindo lo que les voy a rogar Wenu rey chao ta ngillatulelafin $\mathrm{Al}$ padre rey del cielo lo voy a rogar

Tüfa chi pu wingka tüfa chi pu ülmen müley

Están estos blancos, estos hombres importantes.

Küpayngün yefuy nga küpayngün, ye koylazunguürpayngü

Vinieron, llevaron por delante, vinieron, de vuelta vinieron acá hablando mentiras.

Inchiñ, fey, ta kuyfi ñi koyla chumelkewel ta tüfa chi tüfa chi wingka ka mülelo

A nosotros, eso, hace rato que están acostumbrados a mentir estos winkas que hay Mapu zungu mo, 'obernador, presidente 'e la nación, ye koyla mu ta miawaymün

En tema de tierra, gobernador, presidente de la nación, hasta cuándo van a andar con mentiras. Potrikawayngün ta, koyla mu, pu paysano femngengey, kuyfi ta $\tilde{n} i$ femngen Andan envolviendo con mentira, a los paisanos le hacen así [como se les antoja], hace 
rato es así.

Fey, inche feymu fotüm

llazküllazküñmafiñ kachu pu

wingka ye koyla ñi küpan

Así, yo por eso hijo me enojé

con los cinco winkas, pura

mentira traen.

Bueno, fey, kom, kom

recomendaluafin dio mu tüfa chi

zungu, niein tati

Bueno, eso, todo, todo lo voy a recomendar a dios, esta palabra tenemos

Fey ta eymu ta, kiñeleay in

rakizuam pin, fey ta fey

Eso, a ustedes dos digo: sea uno nuestro pensamiento digo, eso. Chumnechi zungu müley afule, newenmanmuaiñ fürenemuayiñ

Cualquier palabra hay, que termine, danos fuerza, favorécenos.

En Marisa Malvestitti. Kiñe Rakizuam: textos mapuche de la línea sur. Buenos Aires: Facultad de Filosofía y Letras, 164-167, 2005.

\section{Todos somos mapuches, pinches bueyes (fragmento)}

Elizabeth Neira

No se trata de oportunismo, mi querido amigo, como me lo sugirió hace unos días, ebrio y baboso, midiendo el mundo con la miopía de su propia mezquindad, un colega de las letras, copa de champagne en la mano, en un animado vernisage.

No se trata tampoco de resentimiento ya que procuro actuar de acuerdo a mis ideas y pasiones cuando éstas aparecen; no las caliento en una olla, no hago con ellas un caldo de cultivo. No soy una pregonera de las bondades de la violencia, pero tampoco soy ilusa y sé que jamás ha habido cambio social que se haya impuesto por la buena voluntad o la evolución espiritual de los empresarios o la clase gobernante.

No creo en el odio de clases, ni en la superioridad de ninguna raza, menos aún en algún tipo de pureza, así como tampoco en las fronteras dibujadas con sangre.

Apoyo la resistencia mapuche por la simple y sencilla razón, compañero, usted que mira todo con la suspicacia de su miseria, porque me reconozco disidente de este sistema depredador impuesto por ideologías que considero causante de la máxima infelicidad humana.

En Lof sitiado. Homenaje Poético al Pueblo Mapuche de Chile. Jaime Huenún (comp.) Santiago: Lom Ediciones, 128, 2011 